\title{
Model Regresi Semiparametrik Spline Hasil Produksi Padi di Kabupaten
} Lombok Timur

\author{
Bidayani $^{a}$, Mustika Hadijati ${ }^{b}$, Nurul Fitriyani ${ }^{c, *}$ \\ ${ }^{a}$ Program Studi Matematika, Fakultas Matematika dan Ilmu Pengetahuan Alam, Universitas Mataram, Mataram, \\ 83125, Indonesia. Email: bidayani2@gmail.com \\ ${ }^{b}$ Program Studi Matematika, Fakultas Matematika dan Ilmu Pengetahuan Alam, Universitas Mataram, Mataram, \\ 83125, Indonesia. Email: mustika.hadijati@unram.ac.id \\ c, * Program Studi Matematika, Fakultas Matematika dan Ilmu Pengetahuan Alam, Universitas Mataram, Mataram, \\ 83125, Indonesia. Email: nurul.fitriyani@unram.ac.id
}

\begin{abstract}
A B S T R A C T
Rice is a very important staple food in Indonesia that must be maintained throughout the year. However, in recent years, Indonesia, known for its natural wealth, has become one of the countries importing rice. This is because rice consumption in Indonesia continues to increase every year, while the production of rice produced is insufficient for the consumption of the Indonesian people. This aim of this study were to determine the semiparametric spline regression model in the analysis of factors that influence rice production in East Lombok District in 2014 and to find out what factors influence the rice production results. The method used was semiparametric spline regression, with the selection of the optimum knot points using Generalized Cross Validation. The results obtained indicate that the variable that significantly affects rice production was the height of the area above sea level, with the determination coefficient value of $99.71 \%$ and the Root Mean Square Error of Prediction value of 41.65.
\end{abstract}

Keywords: Generalized Cross Validation, Rice Production, Semiparametric Regression, Spline.

\section{A B S T R A K}

Beras merupakan suatu sumber bahan makanan pokok penting yang harus tetap terjaga ketersediannya sepanjang tahun. Namun untuk tahun-tahun terakhir ini Indonesia yang dikenal dengan kekayaan alamnya, menjadi salah satu negara pengimpor beras. Hal ini dikarenakan konsumsi beras di indonesia terus meningkat setiap tahunnya, sedangkan produksi beras yang dihasilkan kurang mencukupi konsumsi masyarakat Indonesia. Penelitian ini dilakukan dengan tujuan untuk menentukan model regresi semiparametrik spline pada analisis faktor-faktor yang mempengaruhi hasil produksi padi di Kabupaten Lombok Timur tahun 2014, serta mengetahui faktor-faktor apa saja yang mempengaruhi hasil produksi padi tersebut. Metode yang digunakan adalah regresi semiparametrik spline dengan pemilihan titik knot optimum menggunakan Generalized Cross Validation. Hasil yang diperoleh menunjukkan bahwa variabel yang secara signifikan mempengaruhi hasil produksi padi adalah ketinggian wilayah

* Corresponding author.

Alamat e-mail: nurul.fitriyani@unram.ac.id 
dari permukaan laut, dengan nilai koefisien determinasi sebesar 99,71\% dan nilai Root Mean Square Error of Prediction sebesar 41,65.

Kata kunci: Generalized Cross Validation, Produksi Padi, Regresi Semiparametrik, Spline.

Diserahkan: 12-06-2019; Diterima: 27-06-2019;

Doi: https://doi.org/10.29303/emj.v1i1.31

\section{Pendahuluan}

Tanaman padi merupakan tanaman yang penting bagi bangsa Indonesia karena mempengaruhi hajat hidup orang banyak (Francisco, dkk., 2017). Keberadaan padi sebagai makanan pokok bagi hampir seluruh bangsa Indonesia, harus tetap terjaga sepanjang tahun dengan memanfaatkan kekayaan sumber daya alam yang dimiliki dan kecerdasan sumber daya manusianya dalam mengolah kekayaan tersebut. Namun untuk tahun-tahun terakhir ini Indonesia yang dikenal dengan kekayaan alamnya menjadi salah satu negara pengimpor beras (BPS, 2019). Zaeroni dan Dewi (2016) mengatakan konsumsi beras di indonesia terus meningkat setiap tahunnya, sedangkan produksi beras yang dihasilkan kurang mencukupi konsumsi masyarakat Indonesia, sehingga pemerintah mengambil keputusan untuk melakukan impor. Oleh karena itu, dapat disimpulkan hasil produksi padi tidak dapat menyeimbangi peningkatan jumlah penduduk Indonesia.

Provinsi Nusa Tenggara Barat (NTB) terdiri dari 2 pulau besar, yaitu Pulau Lombok dan Pulau Sumbawa, dan merupakan salah satu daerah penghasil padi dan sebagian daerah untuk pengadaan stok pangan nasional dengan berbagai program. Program-program tersebut berhasil meningkatkan produksi dan berswasembada beras bahkan surplus, sehingga dapat mengekspor ke berbagai provinsi di tanah air (BPS, 2001).

Kabupaten Lombok Timur merupakan kabupaten paling luas di Pulau Lombok, dengan luas 1605,55 $\mathrm{km}^{2}$ (BPS, 2016). Kabupaten Lombok Timur bagian utara merupakan daerah pertanian yang subur dan merupakan lereng Gunung Rinjani dengan ketinggian 3.726 meter (Dainty, dkk., 2016). Secara umum pola penggunaan lahan di Kabupaten Lombok Timur didominasi oleh lahan pertanian, hal ini terkait dengan mata pencaharian sebagian besar bergerak dibidang pertanian dan tanaman pangan.

Sektor pertanian merupakan sektor primer penunjang ekonomi rakyat membutuhkan perhatian yang serius dari berbagai pihak, agar dapat terus menopang kehidupan ekonomi sebagian besar penduduk Kabupaten Lombok Timur karena bertambahnya penduduk Lombok Timur setiap tahun maka bertambah juga kebutuhan akan beras (BPS, 2014). Untuk mencegah produksi padi menurun ataupun menjaga agar produksi padi Lombok Timur tetap stabil bahkan meningkat adalah dengan cara mengetahui faktor-faktor apa saja yang mempengaruhi hasil produksi padi di Lombok Timur, sebagai upaya dalam mengurangi impor dan mencapai hasil akhir yaitu swasembada pangan. Oleh karenanya, pada penelitian ini dibahas faktor-faktor apa saja yang mempengaruhi hasil produksi padi di Lombok Timur tahun 2014.

Berdasarkan penelitian Ishaq, dkk. (2016), faktorfaktor yang mempengaruhi produksi padi yaitu luas panen padi, curah hujan, luas puso padi, realisasi pupuk bersubsidi, dan ketinggian rata-rata dari permukaan laut. Damayanti (2013) menyatakan faktor-faktor yang mempengaruhi produksi padi sawah lahan irigasi adalah luas lahan, penggunaan benih, penggunaan pupuk urea, penggunaan pupuk phonska, penggunaan pestisida, penggunaan tenaga kerja dalam keluarga, umur petani, frekuensi bimbingan, dan dummy irigasi.

Dalam menganalisis faktor-faktor yang mempengaruhi hasil produksi padi, dapat digunakan analisis regresi. Analisis regresi merupakan metode yang mempelajari tentang pola hubungan antara variabel respon dan variabel prediktor yang ditunjukan dengan scatterplot sebagai bentuk kurva regresi. Kurva regresi dikelompokkan menjadi tiga, yaitu kurva yang diasumsikan diketahui bentuknya yang didekati dengan regresi parametrik, kurva yang diasumsikan tidak diketahui bentuknya yang didekati dengan regresi nonparametrik, dan kurva yang sebagian diketahui bentuknya dan sebagian tidak diketahui bentuknya (acak), yaitu regresi semiparametrik (Budiantara, 2005).

Berdasarkan analisis awal yang telah dilakukan, diketahui bahwa hubungan antara hasil produksi padi dengan jumlah bibit dan luas panen membentuk garis lurus, artinya dapat dilakukan analisis dengan pendekatan parametrik. Sedangkan hubungan hasil produksi padi dengan jumlah curah hujan dan ketinggian dari permukaan laut cenderung acak, artinya dapat dilakukan analisis dengan pendekatan nonparametrik. Dengan memperhatikan hal tersebut, maka analisis mengenai faktor-faktor yang mempengaruhi produksi padi dapat dilakukan dengan pendekatan semiparametrik, yang merupakan gabungan dari pendekatan parametrik dan nonparametrik. 
Dalam regresi nonparametrik terdapat beberapa teknik estimasi yang dapat dilakukan diantaranya pendekatan histogram, estimator kernel, estimator deret orthogonal, analisis wavelet, estimator Multivariate Analysis Regression Spline (MARS), estimator deret Fourier, estimator spline, dan lain-lain (Merry, dkk., 2017). Spline sendiri adalah salah satu metode estimasi regresi nonparametrik yang sangat baik dalam memodelkan data yang polanya berubahubah pada sub interval tertentu, karena memiliki sifat tersegmen atau terpotong-potong, yang dengan sifat tersebut spline memiliki fleksibilitas yang tinggi dari model polinom biasa. Hal ini menyebabkan regresi spline dapat menyesuaikan diri secara lebih efektif terhadap karakteristik lokal suatu fungsi, sehingga didapatkan hasil yang mendekati kebenaran yang diperoleh dengan memilih titik knot yang optimal. Salah satu metode yang baik digunakan untuk memperoleh titik knot yang optimal adalah metode Generalized Cross Validation (GCV) (Eubank, 1999). Secara teoritis bahwa GCV mempunyai sifat optimal asimtotik, yang tidak dimiliki oleh metode lain. Karena kelebihannya ini metode GCV menjadi sangat terkenal dalam regresi nonparametrik dan semiparametrik. (Wibowo, dkk., 2009).

\section{Analisis Regresi}

\subsection{Regresi Parametrik}

Regresi parametrik merupakan suatu metode yang sederhana dalam kajian analisis regresi, namun disisi lain menuntut terpenuhinya berbagai asumsi yang sangat ketat, salah satunya adalah bentuk kurva regresi diketahui, misalnya linear, kuadratik, kubik, polinomial derajat- $p$, eksponen, dan lain-lain. Pengetahuan terhadap bentuk kurva regresi memudahkan dalam memilih salah satu bentuk keluarga kurva atau fungsi regresi yang memungkinkan dari beberapa alternatif yang ada, kemudian menempatkan fungsi regresi tersebut dalam proses inferensi. Jika bentuk kurva atau fungsi regresi yang dipilih bisa tepat, maka analisis regresi parametrik akan lebih menguntungkan, khususnya metode inferensinya dan interpretasi parameternya akan lebih sederhana. Oleh karena itu, analisis regresi parametrik lebih sering digunakan apabila terdapat informasi tentang bentuk kurva regresinya.

Secara matematis fungsi regresi parametrik bisa ditulis dengan persamaan sebagai berikut.

$$
y_{i}=g\left(x_{i}, \beta_{j}\right)+\varepsilon_{i}, i=1,2, \ldots n, j=1,2, \ldots, p
$$

dengan $y_{i}$ adalah respon ke- $i, x_{i 1}, x_{i 2}, \ldots, x_{i p}$ adalah variabel prediktor, fungsi $g\left(x_{i}, \beta_{j}\right)$ adalah fungsi regresi parametrik atau kurva regresi parametrik dengan parameter $\beta$ dan jumlah parameter $p, \varepsilon_{i}$ adalah error acak yang diasumsikan berdistribusi normal independen dengan rata-rata nol dan variansi $\sigma^{2}$ (Eubank, 1999).

\subsection{Regresi Nonparametrik}

Regresi nonparametrik merupakan merupakan salah satu pendekatan yang digunakan untuk mengetahui pola hubungan antara variabel prediktor dan respon yang tidak diketahui kurva regresinya atau tidak terdapat informasi masa lalu yang lengkap tentang bentuk pola data. Berdasarkan kenyataan tersebut, maka secara visual pola yang diberikan oleh variabel prediktor $z$ dan variabel respon $y$ tidak mempunyai pola yang jelas. Pendekatan regresi nonparametrik memiliki fleksibilitas yang tinggi, karena data diharapkan mencari sendiri bentuk estimasi kurva regresinya tanpa dipengaruhi oleh faktor subyektifitas peneliti.

Regresi nonparametrik adalah model regresi yang sangat tepat digunakan untuk mendeteksi adanya sifat nonlinearitas dan adanya hubungan nonlinear dalam model (Eubank, 1999). Pada pendekatan regresi nonparametrik ini akan menggunakan asumsi yang longgar sehingga peneliti tidak memaksakan memakai bentuk kurva yang kaku namun membiarkan data yang mencari bentuk estimasi dari kurva regresinya. Kurva regresi dalam regresi nonparametrik diasumsikan halus dan termuat dalam suatu ruang fungsi tertentu. Beberapa model regresi nonparametrik yang banyak digunakan diantaranya spline, kernel, deret fourier, dan Multivariate Analysis Regression Spline (MARS).

Secara umum model regresi nonparametrik memiliki bentuk fungsi sebagai berikut.

$$
y_{i}=f\left(z_{i}\right)+\varepsilon_{i} ; i=1,2, . . n
$$

dengan $y_{i}$ adalah respon ke- $i, f\left(z_{i}\right)$ adalah fungsi regresi atau kurva regresi yang tidak diketahui bentuknya, serta $\varepsilon_{i}$ adalah sisaan yang diasumsikan independen dengan nilai tengah nol dan varian $\sigma^{2}$.

\subsection{Regresi Semiparametrik}

Regresi semiparametrik adalah metode statistika yang merupakan gabungan antara regresi parametrik dan regresi nonparametrik (Budiantara, 2005). Apabila diasumsikan bahwa bentuk kurva regresi sebagian diketahui dan sebagian tidak diketahui, maka digunakan pendekatan regresi semiparametrik. Model regresi semiparametrik dapat ditulis sebagai berikut.

$$
y_{i}=g\left(x_{i}, \beta_{j}\right)+f\left(z_{i}\right)+\varepsilon_{i} ; i=1,2, \ldots n
$$

dimana $y_{i}$ adalah variabel respon ke- $i, g\left(x_{i}, \beta_{j}\right)$ merupakan fungsi komponen parametrik, $f\left(z_{i}\right)$ merupakan fungsi komponen nonparametrik yang 
tidak diketahui bentuk kurvanya dan $\varepsilon_{i}$ adalah error acak, dimana $\varepsilon_{i} \sim N\left(0, \sigma_{2}\right)$.

\subsection{Regresi Semiparametrik Spline Truncated}

Salah satu metode estimasi regresi nonparametrik adalah spline truncated. Spline truncated merupakan pendekatan regresi nonparametrik dan semiparametrik yang banyak digunakan. Spline truncated merupakan potongan-potongan polinomial yang memiliki sifat tersegmen dan kontinu. Salah satu kelebihan spline truncated adalah model ini cenderung mencari sendiri estimasi data kemanapun pola data tersebut bergerak. Kelebihan ini terjadi karena dalam spline truncated terdapat titik-titik knot, yaitu titik perpaduan bersama yang menunjukkan terjadinya perubahan pola perilaku data (Eubank, 1999).

Jika diberikan data berpasangan $\left(x_{i}, y_{i}, z_{i}\right), i=1,2, \ldots, n$, dimana $y_{i}$ adalah variabel respon sedangkan $x_{i}$ adalah variabel prediktor yang diasumsikan mengikuti pola parametrik linear dan $z_{i}$ adalah variabel prediktor yang mengikuti pola nonparametrik. Pola hubungan $x_{i}, y_{i}$, dan $z_{i}$ dapat dinyatakan dalam model regresi seperti persamaan berikut.

$$
y_{i}=\beta_{0}+\beta_{1} x_{i 1}+\ldots+\beta_{q} x_{i q}+f\left(z_{i}\right)+\varepsilon_{i}
$$

dengan $i=1,2, \ldots, n$ variabel prediktor $x_{i j}, j=1,2 \ldots, q$ diasumsikan mempunyai hubungan parametrik linear dengan variabel respon $y_{i}$. Sedangkan variabel prediktor $z_{i}$ mempunyai hubungan secara nonparametrik dengan variabel respon $y_{i}$.

Selanjutnya jika kurva regresi $f\left(z_{i}\right)$ pada persamaan (4) dihampiri dengan kurva regresi spline truncated dengan titik-titik knot $K_{1}, K_{2}, \ldots, K_{r}$ maka dapat ditulis sebagai berikut.

$$
f\left(z_{i}\right)=\sum_{j=1}^{m} \sigma_{j} z_{i}^{j}+\sum_{k=1}^{r} \sigma_{k+m}\left(z_{i}-K_{k}\right)_{+}^{m}
$$

dengan $\sigma$ adalah parameter-parameter model dan fungsi truncated $\left(z_{i}-K_{k}\right)_{+}^{m}$ diberikan oleh persamaan (6) dibawah ini.

$$
\left(z_{i}-K_{k}\right)_{+}^{m}=\left\{\begin{array}{cl}
\left(z_{i}-K_{k}\right)^{m} & , z_{i} \geq K_{k} \\
0 & , z_{i}<K_{k}
\end{array}\right.
$$

Kurva regresi $f\left(z_{i}\right)$ merupakan kurva regresi nonparametrik spline truncated derajat $m$ dengan banyaknya titik knot $r$. Derajat $m$ merupakan derajat pada persamaan polinomial. Kurva regresi polinomial derajat 1 biasa disebut dengan kurva regresi linear, kurva regresi polinomial derajat 2 biasa disebut dengan kurva regresi kuadratik, sedangkan kurva regresi polinomial derajat 3 biasa disebut dengan kurva regresi kubik. Titik-titik knot adalah titik-titik knot yang menunjukkan perubahan pola perilaku dari kurva pada sub-sub interval yang berbeda, dimana:

$$
K_{1}<K_{2}<\ldots<K_{r}
$$

Wibowo, dkk. (2009) menyatakan bahwa pada dasarnya untuk memperoleh estimator spline pada model regresi terdapat dua pendekatan optimasi, yaitu estimator spline yang diperoleh berdasarkan optimasi penalized least square (PLS) dan estimator spline yang diperoleh berdasarkan optimasi least square (LS) dengan menggunakan fungsi keluarga yang memuat titik-titik knot. Apabila estimator spline yang diperoleh berdasarkan optimasi PLS, maka persoalan utama dalam estimator ini adalah pemilihan parameter penghalus yang optimal. Sedangkan apabila estimator spline yang diperoleh dengan optimasi LS, maka persoalan utama dalam estimator ini adalah pemilihan titik-titik knot yang optimal.

Bentuk kurva regresi spline dangat dipengaruhi oleh parameter penghalus. Terdapat beberapa metode parameter penghalus yang dapat digunakan metode cross validation (CV), metode unbiased risk (UBR), dan metode generalized cross validation (GCV) (Wibowo, dkk., 2009). Menurut Budiantara (2005) salah satu metode yang baik digunakan untuk memperoleh titik knot yang optimal adalah metode Generalized Cross Validation (GCV). Secara teoritis bahwa GCV mempunyai sifat optimal asimtotik, yang tidak dimiliki oleh metode lain. Karena kelebihannya ini metode GCV menjadi sangat terkenal dalam regresi nonparametrik dan semiparametrik dan sering digeneralisasikan serta disesuaikan bentuk formulanya oleh para peneliti dalam estimator spline lain untuk memilih parameter penghalus optimal (Wibowo, dkk., 2009). Selain itu, Fitriyani dan Budiantara (2014) juga ditunjukkan bahwa metode GCV memberikan hasil yang lebih baik dibandingkan metode $\mathrm{CV}$, dengan memperhatikan kriteria pemilihan model terbaik serta pengujian asumsi residual model data fertilitas di Jawa Timur. Adapun fungsi persamaan GCV sebagai berikut.

$$
G C V\left(K_{1}, \ldots, K_{r}\right)=\frac{\operatorname{MSE}\left(K_{1}, \ldots, K_{r}\right)}{\left(n^{-1} \operatorname{tr}\left[1-A\left(K_{1}, \ldots, K_{r}\right)\right]\right)^{2}}
$$

dengan $K_{i}$ merupakan titik-titik knot dan $n$ adalah jumlah data sedangkan $A\left(K_{1}, K_{2}, \ldots, K_{r}\right)$ adalah matrik diperoleh dengan persamaan sebagai berikut.

$$
A\left(K_{1}, K_{2}, \ldots, K_{r}\right)=X\left(X^{1} X\right)^{-1} X^{1}
$$




\section{Data dan Metode}

Data penelitian yang digunakan merupakan data sekunder dari Badan Pusat Statistik Provinsi Nusa Tenggara Barat, meliputi seluruh kecamatan yang berada di Lombok Timur, Provinsi Nusa Tenggara Barat, meliputi data hasil produksi padi ( $\mathrm{Y}$ dalam ton), luas panen padi ( $\mathrm{X}_{1}$ dalam hektar), jumlah bibit ( $\mathrm{X}_{2}$ dalam ton), ketinggian rata-rata dari permukaan laut $\left(\mathrm{Z}_{1}\right.$ dalam meter $)$, dan curah hujan $\left(\mathrm{Z}_{2}\right.$ dalam $\mathrm{Mm})$.

Langkah-langkah penelitian ini antara lain: (1) mengumpulkan data dan referensi; (2) menganalisis statistika deskriptif data; (3) membentuk dan menguji pola hubungan antar variabel; (4) menentukan komponen parametrik dan komponen nonparametrik; (5) melakukan pemodelan produksi padi menggunakan regresi semiparametrik spline dengan 1 knot, 2 knot, dan 3 knot; (6) memilih model terbaik berdasarkan titik knot optimal menggunakan karakteristik nilai GCV paling minimum dan nilai koefisien determinasi paling besar; (7) menguji signifikansi parameter model; (8) menguji asumsi residual model; dan (9) menginterprestasi model dan menarik kesimpulan.

\section{Hasil dan Pembahasan}

Informasi dasar mengenai data penelitian terlihat dari statistik deskriptif data yang tertera pada Tabel 1.

Tabel 1 - Statistik Deskriptif Data

\begin{tabular}{cccr}
\hline Variabel & Minimum & Maksimum & Rata-rata \\
\hline$y$ & 4203 & 29630 & 15981,7 \\
$x_{1}$ & 1063 & 5995 & 3409,0 \\
$x_{2}$ & 33 & 185 & 105,9 \\
$x_{3}$ & 4 & 1200 & 263,5 \\
$x_{4}$ & 161 & 1813 & 1113,1 \\
\hline
\end{tabular}

Model regresi parametrik dalam hal ini didekati dengan regresi linier berganda, seperti yang tertera pada persamaan (1). Estimasi kurva regresi linear berganda untuk hasil produksi padi tahun 2014 di Kabupaten Lombok Timur diberikan sebagai berikut.

$$
\begin{aligned}
\hat{y}_{i}= & -1070,33+3,66 x_{i 1}+39,15 x_{i 2}-0,46 x_{i 3} \\
& +0,49 x_{i 4}
\end{aligned}
$$

Pengujian parameter model regresi parametrik secara simultan yang dilakukan menunjukkan bahwa model yang dihasilkan tepat, atau terdapat paling sedikit satu variabel prediktor yang signifikan dalam model. Model ini menghasilkan koefisien determinasi $\left(R^{2}\right)$ sebesar $99,2 \%$, yang berarti bahwa variasi dari variabel respon dapat dijelaskan oleh keempat variabel prediktor sebesar 99,2 persen, sedangkan sisanya 0,8 persen dijelaskan oleh faktor lain.

Selanjutnya, pengujian parameter model secara parsial menunjukkan bahwa tidak terdapat variabel prediktor $x_{i}$ yang signifikan terhadap variabel respon $y$. Oleh karena itu, dapat disimpulkan bahwa metode parametrik kurang tepat untuk digunakan dalam memodelkan hasil produksi padi dengan variabel prediktor yang akan diteliti.

Identifikasi pola hubungan antara variabel respon dengan masing-masing variabel prediktor yang dapat digambarkan dengan scatter plot berikut.

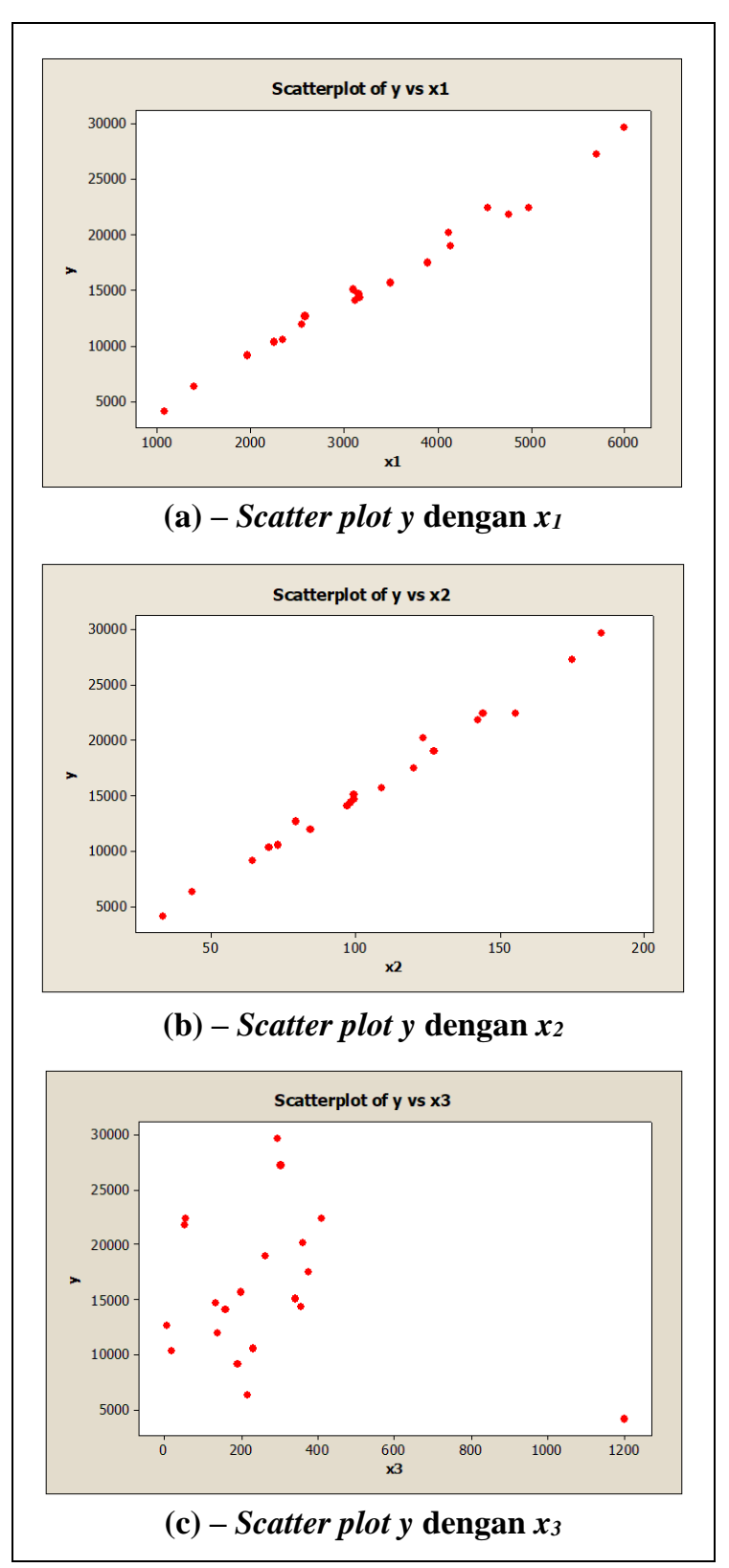




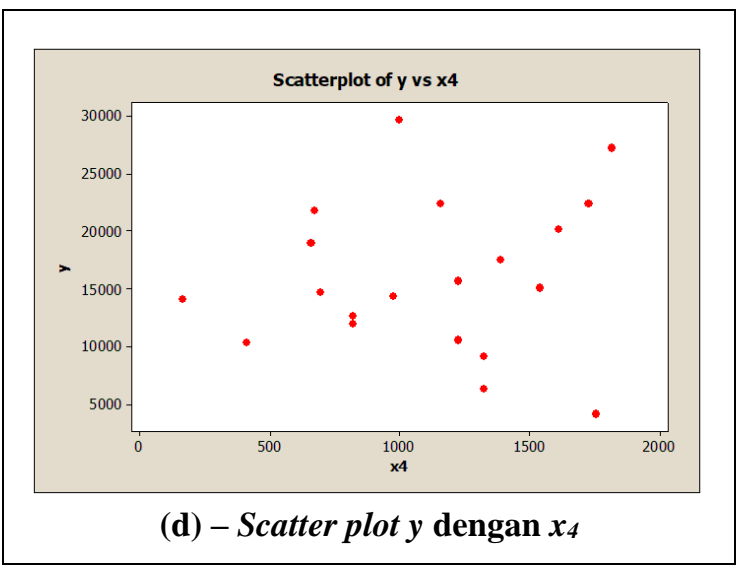

Gambar. 1 - Scatter plot antara variabel respon $y$
dengan masing-masing variabel prediktor $x_{i}$

Gambar 1 menunjukkan bentuk pola hubungan antara variabel hasil produksi padi $(y)$ dengan variabel-variabel prediktornya. Terlihat bahwa Gambar 1 (a) dan (b) menunjukkan pola hubungan yang cenderung membentuk pola tertentu, yaitu cenderung membentuk garis lurus atau linier, sehingga variabel $x_{1}$ dan $x_{2}$ didekati dengan komponen parametrik.

Selanjutnya, Gambar 1 (c) dan (d) menunjukkan pola hubungan yang cenderung tidak membentuk pola tertentu, sehingga variabel $x_{3}$ dan $x_{4}$ didekati dengan komponen nonparametrik. Pola hubungan yang terlihat cenderung mengalami perubahan perilaku pada sub interval tertentu, sehingga dapat dianalisis lebih lanjut dengan pendekatan nonparametrik spline.

Penentuan pola hubungan ini juga didukung pula dengan pengujian model parametrik (linear, quadratic, compound, growth, logarithmic, cubic, S, exponential, inverse, power, dan logistic) dan nonparametrik yang dilakukan untuk masing-masing variabel prediktor.

Oleh karena hubungan antara variabel prediktor yang mempengaruhi hasil produksi padi $(y)$ terdiri atas komponen parametrik dan nonparametrik, maka pemodelan dilakukan dengan pendekatan semiparametrik, yang merupakan gabungan antara regresi parametrik dan nonparametrik. Pendekatan yang digunakan adalah pendekatan semiparametrik spline dengan fungsi potongan (truncated) linear.

Pemilihan model regresi spline terbaik dilakukan dengan memilih titik knot optimal, sesuai dengan lokasi dan banyaknya titik knot yang menghasilkan GCV minimum. Gambar 1 (c) dan (d) menunjukkan bahwa data mengalami perubahan perilaku pola data pada tiga interval berlainan, sehingga dilakukan pengujian dengan 1 titik knot, 2 titik knot, dan 3 titik knot. Tabel 2 menunjukkan nilai GCV minimum dari masing-masing 1 titik knot, 2 titik knot, dan 3 tititk knot yang diperoleh.

Tabel 2 - Nilai GCV Minimum

\begin{tabular}{rc}
\hline Jumlah Knot & Nilai GCV Minimum \\
\hline Satu titik knot & 661597,5 \\
Dua titik knot & 505076,9 \\
Tiga titik knot & 393523,6 \\
\hline
\end{tabular}

Tabel 2 menunjukkan bahwa nilai GCV minimum dari masing-masing nilai GCV minimum dari pilihan jumlah knot yang digunakan terletak pada model dengan 3 titik knot, dengan nilai GCV sebesar 393523,6. Titik knot yang dihasilkan ini selanjutnya digunakan dalam pemodelan hasil produksi padi.

Selanjutnya, estimasi parameter model spline truncated dengan tiga knot dengan menggunakan metode kuadrat terkecil atau least squre (LS) menghasilkan model sebagai berikut.

$$
\begin{aligned}
\hat{y}_{i} & =-0.14+4.09 x_{1}+29.56 x_{2}-42.74 z_{1} \\
& +70.77\left(z_{1}-570,53\right)_{+}^{1}-29.19\left(z_{1}-633,47\right)_{+}^{1} \\
& +0.84\left(z_{1}-696,42\right)_{+}^{1}-2.36 z_{2} \\
& +7.66\left(z_{2}-943,53\right)_{+}^{1}-5.49\left(z_{2}-1030,47\right)_{+}^{1} \\
& +0.70\left(z_{2}-1117,42\right)_{+}^{1}
\end{aligned}
$$

Model spline truncated yang diperoleh mempunyai nilai koefisien determinasi $R^{2}$ sebesar $99,7 \%$. Hal ini berarti bahwa model dapat menjelaskan keragaman hasil produksi padi di Kabupaten Lombok Timur sebesar 99,7\%, sementara sisanya dipengaruhi dari luar variabel prediktor yang digunakan. Kriteria yang diperoleh menunjukkan bahwa regresi dengan memperhatikan unsur hasil yang lebih baik dibandingkan dengan menggunakan regresi dengan pendekatan parametrik.

Pengujian parameter model regresi nonparametrik secara simultan yang dilakukan menunjukkan bahwa model yang dihasilkan tepat, atau terdapat paling sedikit satu variabel prediktor yang signifikan dalam model, sedangkan pengujian parameter model secara parsial menunjukkan bahwa hanya parameter regresi untuk variabel $z_{1}$ yang secara signifikan mempengaruhi variabel respon $y$. Oleh karena itu, diperoleh model berikut.

$$
\begin{aligned}
\hat{y}_{i}= & -42.74 z_{1}+70.77\left(z_{1}-570,5\right)_{+}^{1} \\
& -29.19\left(z_{1}-633,47\right)_{+}^{1}
\end{aligned}
$$

Dalam rangka menguji kelayakan model yang diperoleh, perlu untuk dilakukan pengujian asumsi 
residual. Hasil yang diperoleh menunjukkan bahwa pengujian asumsi residual identik menggunakan uji Glejser terpenuhi; pengujian asumsi independen menggunakan plot Autocorrellation Function (ACF) dan pengujian Ljung-Box terpenuhi; dan pengujian asumsi normal menggunakan Kolmogorov-Smirnov terpenuhi.

Selanjutnya, dengan didasarkan pada persamaan (6), maka model pada persamaan (8) dapat ditulis dalam bentuk fungsi potongan (truncated) pada persamaan (10).

$$
\hat{y}= \begin{cases}-42,74 z_{1} & ; z_{1}<570,53 \\ 28,03 z_{1}-40374,78 & ; 570,53 \leq z_{1}<633,47 \\ -1,16 z_{1}-21886,17 & ; 633,47 \leq z_{1}<696,42 \\ -0,32 z_{1}-22470,88 & ; z_{1} \geq 696,42\end{cases}
$$

dengan $y$ menunjukkan data hasil produksi padi (dalam ton) dan $z_{l}$ menunjukkan data ketinggian ratarata dari permukaan laut (dalam meter). Berdasarkan model yang diperoleh pada persamaan (10), diperoleh kesimpulan bahwa lahan yang cocok untuk mendapatkan hasil produksi padi yang optimal ditinjau dari dari segi ketinggian wilayah dari permukaan laut adalah wilayah dengan dengan ketinggian berada diantara 570,53 meter dan 633,47 meter.

\section{Kesimpulan}

Hasil produksi padi di Kabupaten Lombok Timur tahun 2014 secara signifikan dipengaruhi oleh ketinggian wilayah dari permukaan laut, sehingga untuk memperoleh hasil yang optimal perlu untuk memperhatikan ketinggian wilayah.

\section{DAFTAR PUSTAKA}

Francisco, M. T., dkk. (2017). Analisis Pendapatan Usaha tani Padi Sawah Dengan System of Rice Intensification Di Desa Empat Balai Kecamatan Kuok Kabupaten Kampar. Jurnal Ilmiah Pertanian. Vol. 13, No. 2.

Badan Pusat Statistik (BPS). (2019). Impor Beras menurut Asal Negara, 2000-2017. https://www.bps.go.id/, diakses Juni 2019.

Zaeroni, R. dan Dewi, S. R. (2016). Pengaruh Produksi Beras, Konsumsi Beras, dan Cadangan Devisa Terhadap Impor Beras di Indonesia. Jurnal Ekonomi Pembangunan Universitas Udayana. Vol. 5, No. 9.
Badan Pusat Statistik (BPS). (2001). Nusa Tenggara Barat Dalam Angka 2001. NTB: Badan Pusat Statistik Provinsi NTB.

Badan Pusat Statistik (BPS). (2016). Luas Wilayah dan Persentase Menurut Kabupaten/ Kota di Provinsi NTB. https://ntb.bps.go.id/, diakses Mei 2019.

Dainty, I., dkk. (2016). Analisis Peluang Curah Hujan Untuk Penetapan Pola dan Waktu Tanah Serta Pemilihan Jenis Komoditi yang Sesuai di Desa Masbagik Kecamatan Masbagik Kabupaten Lombok Timur. Jurnal Ilmiah Rekayasa Pertanian Dan Biosistem. Vol. 4, NO. 1.

Badan Pusat Statistik (BPS). (2014). Lombok Timur dalam Angka 2014. Lombok Timur: Badan Pusat Statistik Kabupaten Lombok Timur.

Ishaq, M., dkk. (2016). Analisis Faktor-Faktor yang Mempengaruhi Produksi Padi di Provinsi Jawa Timur Menggunakan Regresi Semiparametrik Spline. Jurnal Sains dan Seni ITS. Vol. 5, No. 2.

Damayanti, L. (2013). Faktor-Faktor yang Mempengaruhi Produksi, Pendapatan dan Kesempatan Kerja pada Usaha Tani Padi Sawah di Daerah Irigasi Parigi Moutong. Jurnal Jurusan Agribisnis Fakultas Peternakan. Universitas Tadulako. Vol. 9, No. 2.

Budiantara, I. N. (2005). Model Keluarga Spline Polinomial Truncated dalam Regresi Semiparametrik. Jurnal Jurusan Statistika FMIPA - ITS, Surabaya.

Merry, N., W., N., Y., dkk. (2017). Aplikasi Model Regresi Semiparametrik Spline Truncated. Jurnal Matematika. Vol. 6(1).

Eubank, R. L. (1999). Nonparametric Regression and Spline Smoothing. New York: Marcel Dekker, Inc.

Wibowo, W., Haryatmi, S., dan Budiantara, I. N. (2009). Metode Kuadrat Terkecil untuk Estimasi Kurva Regresi Semiparametrik Spline. Seminar Nasional Matematika dan Pendidikan Matematika Jurusan Pendidikan Matematika FMIPA UNY. ISBN: 978-979-16353-3-2.

Fitriyani, N. dan Budiantara, I. N. (2014). Metode Cross Validation dan Generalized Cross Validation dalam Regresi Nonparametrik Spline (Studi Kasus Data Fertilitas di Jawa Timur). Prosiding Seminar Nasional Pendidikan Sains. ISBN: 978-602-14702-6-8. 